\title{
INTRODUCTION TO THE LANGUAGE POLICY OF EGYPT*
}

\section{Prof. Mohammad Al-Sharnoubi**}

Arabic language is the key feature of Arabic identity, it is the vehicle, used to convey Arab thought and culture and it is the language of Islam; the prevailing religion in Islamic and Arab countries. Therefore, Arabic is the main means of communication among the peoples of these Islamic and Arab countries. Given its importance in molding the Arab identity with its systems of ideas and thoughts, the government of Egypt made it part of its constitution and strived to use it in all artistic, literal and scientific fields. As part of Egypt's efforts to maintain and promote Arabic language, laws were issued to organize goals and means to promote the usage of Arabic language, leading to the establishment of the Academy of Arabic Language in 1932.

* The National Institute of The Korean Language, International Conference on Language Policy in The World, Seoul, Korea (2011).

** Prof. of Geography, Department of Geography, Faculty of Arts (Fayoum University); General Secretary of Institut d'Egypte.

-1- 
The academy was first established under the name of "The Royal Academy of Arabic Language" on December 13, 1932, under the patronage of the king and the auspice of the ministry of education at that time. Its main goal were the provision of modern sciences, literature and arts in proper Arabic to achieve the ultimate national goal for the Arabic language, which is to support, maintain the integrity, and screen the Arabic language of any loanword, foreign or adventitious word, or slang Arabic language. The academy aims at keeping the Arabic language convenient for daily usage in this modern time and in the future.

Furthermore, the academy has plans to a historical lexicon of the Arabic language as well as other lexicons in different fields of knowledge such as medicine, engineering, biology, geography, anthropology, chemistry, physics and others. The academy plays another major role in developing lexicons and dictionaries including Teaching Dictionary "Al Mo'jam Al-Modaris", the Large Lexicon "Al Mo'jam Al Kabeer", and the Intermediate Lexicon "Al Mo'jam Al-Waseet" with synonymies and Arabic terminologies. The academy also conducted scientific studies of modern Arabic dialects and do research on all aspects of developing, promoting and preserving the Arabic language.

On October 06, 1933, the first royal decree on the academy's matters stated the number of Egyptian members as 20, 5 non-Egyptian Arabs, and 5 western orientalists. Its first meeting was held on January 30, 1934 and maintained its meetings on weekly basis, 9 months a year since then.

The academy formed several general of important, concerned with scientific terms. These committees meet 4 times a month, attended by the most sophisticated scholars and scientists of different fields of knowledge. Each committee hereof is chaired by an academy member and its works and activities are published in the annual journal; the academy's regular magazine.

The academy organizes regular annual conferences, attended by stakeholders, concerned with the issues of Arabic language around the world. It is a continuous 15-day conference. Every years, the attendees 
discuss a certain topic. Participation invitations are sent to all similar institutions around the Arab world. Its sessions are public and held at the big conference room at the academy. Deliverables, works and researches, presented in said conferences, are published as part of the academy's publications.

In 1982, the president of the republic issued a new law to organize the work of the academy. The new law amended and altered some provisions of the royal decree as it turned the academy into an academic, fully independent, legal identity with full accountability for all its financial and administrative affairs, besides all academic issues as far as related to Arabic. It is located in Cairo and reporting to the minister of high education. The new law identifies the goals of the academy as follows:

1. Maintain the integrity of the Arabic language and make it sufficient and appropriate for sciences, literature and arts, and the developed life needs.

2. Consider its etymologies and methods to choose the best means to promote, control and simplify its morphology and syntax and so facilitates its dictation and writing.

3. Study cultural, artistic, literal, and scientific terms and proper foreign names to unify them for Arabic speakers.

4. Consider all means to promote and develop Arabic.

5. Consider issues, referred to the academy in relation to the above goals.

To achieve these goals, tools and approaches have been defined by the new law as follows:

1. Produce modernized and edited lexicons, and special or general scientific lexicons.

2. State and explain the linguistically applicable terms and the etymologies and structures to avoid.

3. Contribute in reviving Arabic heritage in language, literature, arts and other branches of knowledge.

4. Scientifically study ancient and current dialects to serve classic Arabic and scientific research. 
5. Study literary criticism and issues, encourage the literal works by their promotion or organizing seminars and contests with prizes, or any other method.

6. Issue magazines, publications, newsletters or books, which would contain the resolutions of the academy, its works and researches by its members of others in relation to the academy's activities and work.

7. Issue recommendations to competent entities to take the necessary actions to benefit from the deliverables of the academy in service of Arabic language, its simplification and terms standardization.

8. Call for conferences and seminars on the academy's activities and participate in conference and seminars on similar objects.

9. Strengthen the connections and communications with linguistic and scientific academies and authorities inside and outside Egypt.

As for the approach for choosing the academy's members; under the new law maximum 40 Egyptian and 20 non-Egyptians, they must be duly elected of individuals with deep knowledge of linguistics, abundant lingual and scientific production and concerns for the history of the Arab nation and its artistic, literal, lingual and scientific legacy.

Subject to the approval of the president of the republic, members are elected via secret voting in the presence of two thirds of its members; appointment requires absolute majority. The president, vice president and secretary general of the academy shall be elected by secret ballot of its members for a four-year term.

In accordance with the new law, the academy organizes an annual, fortnight meeting, upon a call for meeting by its president and approval of its board. The quorum for this meeting is 50\%; its resolutions and recommendations are issued by the majority of present votes. This meeting shall consider the academy's works and researches made over the year of the meeting.

As per the law, the academy shall appoint Egyptian and nonEgyptian correspondent inside and outside Egypt to help the academy achieve its goals; their appointment is subject to the approval of the minister of high education. The academy shall recruit a sufficient 
number of technical personnel, administrative personnel, editors and labor. The president of the academy shall have the competence of a minister concerning the issues of the academy's staff. The academy has an annual and independent budget.

The technical personnel, assisting in managing the members' works and the operation of the academy shall have a special regulations with their financial payroll and ranks such as first researcher, researcher, assistant researcher and lecturer. They are appointed as per the recruitment laws of the state jobs, after elected and interviewed by an academic commission, formed by the academy and the membership of a university specialist, if necessary. They must have post high degrees, and have published innovative papers on Arabic.

In 2008, an amendment of the existing law was issued to obligate education institutions, entities, supervising cultural services, ministries, public entities, municipal units and others to implement the resolutions of the academy to maintain the integrity of Arabic and standardize its terminologies, in addition to substitute common foreign words. Through its different specialized committees, the academy exerts its efforts to overcome any challenges, follow-up on the implementation of its resolutions and assess obligation to implement said resolutions and recommendations. Montoring such an obligations is one of the tasks, assigned to the academy's employees as per their competences. Violations to these obligations would cause the arise of disciplinary acts; according to the latest amendment, the academy shall establish an office to receive complaints about violations and shall investigate such complaints. The academy shall issue a report on the status of Arabic and the violated resolutions.

\section{The entities of the academy are as follows:}

- The academy's conference: annual as above-mentioned.

- The academy's council: 40 members maximum.

- The academy's office: President, vice-president, secretary and 4 members.

- Committee: 31 .

- Experts: Onboard of committees. 


\section{The academy includes the following committees:}

Large lexicon, Intermediate lexicon, Quran lexicon, Arab Heritage Revival Committee, Language syntax and morphologies, dialects and lingual research, phonation and semantics, literature committee, civilization terms committee, nomination committee, committees for medical, physical, engineering, mathematical, geographical, electronic, IT, biological, oil, legal, pharmaceutical, geological, scientific, agricultural, philosophical, social, psychological, educational, historical, economic, law, anthropological and cultural terminologies. In addition to that there are Arabic writing facilitation committee, historical lingual lexicon and research committee.

Experts' services are sought to assist in the work of these committees upon nomination of concerned academy members and subject to the academy's approval. Said experts are required to suggest and propose specialized terminologies within the specialized committees, and explain and identify them to be approved by the competent committee. Then said terminologies would be presented to the academy's board for approval during its weekly meetings and then presented to its annual meeting for approval. Said experts are chosen of university professors, scholars and competent scientists.

Consequently and based on the above, it is clear the pioneering and influential role of the Academy of the Arabic Language in Egypt along its long history of about 75 years. The academy is still playing a major role in uprising Arabic language to cope with the rapid pace of science, knowledge and technological development. it strives to protect and support the Arabic language for its elite status in the hearts and minds of the Arab and Islamic individual, regardless of his/ her country as the language of the Quran. Therefore, it is important to preserve the Arabic language not only as a means to convey and accommodate different cultures of the world, but also as it has its affiliations to Islamic creed.

$* \quad * \quad *$
$-6-$

